\title{
Práticas sociais e de comunicação de pacientes renais no Facebook da Fundação Pró-Rim
}

\author{
Social and communication practices of renal patients on the \\ Pró-Rim Foundation Facebook
}

\begin{abstract}
Andréia Jacopetti
Mestre pelo Programa de Comunicação e Linguagem da Universidade Tuiuti do Paraná (UTP), Curitiba, PR - Brasil, e-mail: andreiajacopetti@gmail.com
\end{abstract}

\section{Resumo}

As redes colaborativas na internet têm potencializado práticas de comunicação e sociabilidade de públicos ligados aos mais diversos contextos. $\mathrm{Na}$ área da saúde, a participação e a colaboração de pacientes na internet originou o conceito de Health 2.0 e tem crescido graças aos seus potenciais de compartilhamento de experiências, ajuda mútua e interação com outros pacientes. De natureza quantitativa e qualitativa, o estudo em tela tem como corpus os pacientes renais ligados às redes sociais da Fundação Pró-Rim e utiliza como método a realização de entrevistas em profundidade, a observação participante e a Netnografia no Facebook da instituição.

Palavras-chave: Comunicação. Colaboração. Saúde 2.0. pacientes. Redes sociais.

\section{Abstract}

Collaborative networks on the Internet have allowed practices of communication and sociability of groups associated with widely diverging contexts. In the bealth area, the participation and collaboration of patients on the Internet gave rise to the concept of Health 2.0 and has grown due to the potential for sharing experiences, providing mutual aid and interaction with other patients. Of a quantitative and qualitative nature, the study on the screen has as its objective the renal patients linked to the social networks of the Pro-Rim Foundation and uses the method of holding interviews in depth, participating observation and Netnography on the Facebook of the institution.

keywords: Communication. Collaboration. Health 2.0. patient. Social networks. 


\section{Introdução}

A colaboração está ligada à natureza da comunicação dos públicos nos ambientes da segunda geração da internet, denominada como web 2.0. A geração de conteúdo pelos usuários, o incremento da participação na rede, a construção coletiva de conhecimento são algumas das características evidenciadas em meios digitais como blogs, Twitter, Orkut, Facebook, entre outros. Esse tem sido tema de estudo dentro da área de comunicação, pois se insere em um contexto não somente de evolução tecnológica, mas especialmente de mudanças no âmbito dos relacionamentos e práticas sociais por meio da internet.

As mídias sociais na internet estão criando um novo cenário de participação e compartilhamento de informações dentro da área da saúde. Esse movimento, conhecido como Health 2.0, pode ser definido como o uso de software social e a sua capacidade para promover a colaboração entre pacientes, seus médicos e outros stakeholders na saúde. Nele, pessoas com doenças crônicas estão buscando-a para práticas sociais e de comunicação, tais como o compartilhamento de histórias e vivências, interação e relacionamento com profissionais da saúde, direitos, promoção de ajuda mútua, entre outros interesses.

A postura de pacientes crônicos diante da internet tem sido tema de pesquisa na área de comunicação e, especialmente, na área de medicina sobre as mudanças na relação médico-paciente a partir do acesso a blogs, redes sociais, comunidades virtuais específicas e outros sites.

Nesse cenário da comunicação digital, notam-se mudanças nas formas como pacientes relacionam e compartilham informações e conhecimentos. Atualmente, as pessoas que sofrem de alguma doença não têm mais a informação somente no consultório médico. Diante do profissional médico, validam as informações já pesquisadas e compartilhadas nas redes sociais digitais.

A presente pesquisa trata de um estudo exploratório, de caráter descritivo e interpretativo, de natureza quantitativa e qualitativa. Seu objetivo geral é identificar como se dá a participação de pacientes renais da Fundação Pró-Rim no Facebook.

\section{Espaços colaborativos de práticas de comunicação e sociabilidade de pacientes}

Antes de aprofundar a pesquisa sobre os aspectos relacionados à saúde e à internet, buscou-se compreender melhor a respeito do campo de Comunicação em Saúde. Pesquisas indicam que, em termos cronológicos, a construção do campo de estudo voltado à Comunicação e Saúde (BELTRÁN, 2001) surge no século XIX, entre os anos 1820 e 1840, quando o médico escocês Willian Alison e o francês Louis René Villermé estabeleceram relações causais entre doença e condições socioeconômicas e culturais do povo. Eles acreditavam que as condições precárias de vida e de trabalho dos operários eram responsáveis pelas enfermidades que os acometiam e pela baixa expectativa de vida registrada entre eles. Para Beltrán (2001), na visão dos médicos, está implícita a origem do conceito de Comunicação e Saúde, pois privilegiavam a comunicação como ferramenta de promoção da saúde.

Em entrevista concedida à revista eletrônica Comunicação \& Saúde, Pessoni (2005) destaca que, conformeindicação do Handbook of Health Communication, as linhas mais recorrentes de investigação na área, atualmente, são teorização em comunicação para a saúde, comunicação cliente-provedor (relacionada aos planos de saúde), interação médico-paciente, comunicação em saúde para a comunidade (organização, riscos à comunidade, serviço social, comunicação interpessoal do dia a dia e populações marginalizadas), campanhas de saúde, estratégias comunicacionais em saúde, mensagens na mídia eletrônica (narrowcasting), telemedicina, relações públicas em comunicação para a saúde, comunicação para a saúde na mídia e políticas de saúde. Trata-se de uma área que precisa ser bastante desenvolvida e que, inclusive, conta, nos EUA, com a contribuição de diversos programas educacionais em Comunicação para a Saúde, distribuídos pelo país.

No enfoque das práticas sociais e de comunicação nos ambientes digitais, são poucos os estudos existentes, especialmente por pesquisadores da área de comunicação. Esse é um tema que necessita ser ainda explorado, tendo em vista as mudanças sociais provenientes da comunicação colaborativa 
na web $2.0^{1}$ e da maior participação, sobretudo, dos pacientes nos ambientes digitais. Há ainda muitas discussões a serem desenvolvidas nesse cenário sobre a compreensão de como se dá a interação dos pacientes na rede e as suas práticas comunicacionais nos ambientes colaborativos da web 2.0.

Um estudo (RICE, 2001) conduzido com 800 usuários da internet apresentou alguns dados sobre as tendências dos usuários com relação à saúde. Dos entrevistados, 41\% responderam afirmativamente à pergunta se já tinham buscado informação médica na rede. Foi identificado que aqueles que acessam informação de saúde o fazem, em geral, mais de uma vez. As frequências mais altas de acesso eram mais prováveis entre as mulheres e entre os que consideravam possuírem mais habilidades de internet. Sessenta e três por cento dos que responderam ter acessado a internet em busca de informação de saúde afirmaram ter discutido a respeito com outras pessoas, sendo que metade desses o fizeram com médicos e outros profissionais de saúde. Os usuários mais prováveis de discutir informações de saúde com outros eram os mais ricos com maiores habilidades de internet e as mulheres.

Em um artigo sobre essa postura do paciente nos meios digitais, Garbin et al. (2008) discutem até que ponto o paciente portador de inúmeras informações disponíveis na internet consegue alterar a relação médico-paciente, tradicionalmente baseada na assimetria de informações. Destacam que, com a internet, tem surgido um novo ator na área da saúde: o paciente expert. "É um paciente que busca informações sobre diagnósticos, doenças, sintomas, medicamentos e custos de internação e tratamento. [...] Nãoé apenas um paciente informado. Ele se sente, de alguma forma, um entendido em um determinado assunto" (GARBIN; PEREIRA NETO; GUILAM, 2008, p. 581).

Esse comportamento dos pacientes confirma a visão de muitos autores de que, no momento atual da comunicação, o usuário ganha uma força única e que, como público, precisa de uma atenção especial de análise e relacionamento. Nesse cenário da saúde, o "empowerment do paciente" implica muitos aspectos que precisam de análise, como a mudança na relação médico-paciente, a perda da autoridade do profissional especializado, a automedicação dos pacientes, bem como os benefícios da interação e agrupamento social online dos pacientes em torno de comunidades virtuais e grupos de apoio. Uma das recomendações tratadas pelos pesquisadores é a de que os profissionais de saúde estejam cada vez mais atualizados, elaborando pesquisas e conhecendo melhor esse universo em que se insere o paciente e sua relação com a internet. Nesse contexto, os profissionais especializados em comunicação na área da saúde podem, por meio de aplicações de pesquisas com esses públicos e monitoramento de redes sociais, apresentar dados aos médicos que lhes permitam conhecer melhor esse universo onde o seu paciente está inserido.

Faz-se necessário que, nesse âmbito, a comunicação seja ainda mais efetiva, considerando a necessidade de se conhecer profundamente as razões da interação e da busca de informações feitas pelo paciente.

Kotler etal. (2010) tratam da participação de pacientes, destacando que uma maior diversidade de pessoas pode ser influenciada para atingir os outros mais com suas opiniões.

Alguns pacientes começaram a criar blogs ou a enviar mensagens em grupos de discussão; outros estão gravando suas experiências pessoais em podcasts que podem ser baixados para iPods e outros players de áudio portáteis. Páginas pessoais na Internet, Facebook e MySpace e outras tecnologias de rede social são parte da vida da nova geração de pacientes de câncer. Sites de interesse específico deles, como teenswithcancer.org e planetcancer.org, são criados tendo em vista os adultos jovens. Os adolescentes usam os recursos online para conversar sobre seu ressentimento em relação aos medicamentos ou para falar livremente sobre as preocupações sem ter medo de 'não se encaixar' (KOTLER; SHALOWITZ; STEVENS, 2010, p. 413).

Em uma pesquisa recente sobre a participação dos pacientes nesses espaços colaborativos, Fox e Jones (2009) publicaram um relatório com os

\footnotetext{
1 Considerada como a segunda geração da internet, essa denominação foi lançada em outubro de 2004, em uma conferência realizada em São Francisco, EUA, promovida pelas empresas MediaLive e O’Reilly Media.
} 
resultados de uma investigação realizada com 2.253 pacientes.

De acordo com o relatório publicado, constatou-se que dos $61 \%, 59 \%$ já leram comentários de alguém sobre a saúde ou problemas médicos em um grupo de notícias online, site ou blog; consultaram rankings online ou opiniões de médicos ou de outros fornecedores; buscaram informações sobre hospitais ou outras instalações médicas; cadastraram-se para receber atualizações sobre saúde ou problemas médicos, ou ouviram um podcast sobre os problemas de saúde ou médico.

Essa participação dos pacientes na web 2.0 é uma mudança que necessita ser analisada pelos profissionais e pelas instituições de saúde. Consiste na força da colaboração e da participação do usuário dentro da realidade da saúde e envolve um novo panorama no relacionamento entre médicos e pacientes e entre os próprios pacientes. A ajuda mútua, o compartilhamento de histórias e de relatos e o uso da rede para busca de informações são características que sugerem um novo olhar e novas práticas colaborativas na área da comunicação no contexto da saúde.

\section{Participação de pacientes renais nas redes sociais digitais da Fundação Pró-Rim}

Buscando analisar empiricamente a participação de um grupo de pacientes, realizou-se uma pesquisa de campo junto a públicos ligados a uma entidade filantrópica voltada ao tratamento de doentes renais que está entre as sete instituições que mais fazem transplante no Brasil e que passou recentemente pelo processo de convergência tecnológica ${ }^{2}$ voltada à web 2.0. Antes de detalhar a metodologia e a pesquisa realizadas, é necessário contextualizar a entidade cujos públicos - no meio online - estão sendo analisados.
Com serviços ligados ao tratamento de pacientes renais por meio da hemodiálise e do transplante, a Fundação Pró-Rim de Santa Catarina, criada em 22 de dezembro de 1987, é uma entidade de administração privada, sem fins lucrativos. Sua matriz está localizada em Joinville (SC). Atua em cinco unidades em Santa Catarina, Tocantins, possui convênios na cidade de Goiânia, São Paulo e Caxias do Sul. Atende em seu ambulatório de transplantes, pacientes de diversas regiões do Brasil, muitos deles tendo conhecido a instituição por meio de suas ações de Internet.

Em 2010, inseriu-se nas redes sociais online criando perfis no Orkut, Twitter e Facebook. Com isso, a interação com pacientes renais passou por um processo de convergência voltado à participação e colaboração, características essas da web 2.0. Importante salientar que a instituição pesquisada iniciou sua atuação cedo na internet, no cenário 1.0. Todavia, percebe-se que a decisão quanto ao início de sua comunicação nas mídias sociais foi mais lenta se comparada ao mercado, de forma geral. Entende-se que o processo de adesão à web 2.0 ocorreu dessa forma por causa da falta de total conhecimento da organização sobre essa nova realidade das mídias sociais e também da necessidade de se efetuar um planejamento detalhado com preparação do público interno.

Assim como ocorreu na entidade pesquisada, percebe-se que no mercado de saúde esse processo está ocorrendo de forma mais lenta. Ao pesquisar outras experiências de comunicação na web 2.0 na área da saúde, notou-se que a inserção nas redes sociais colaborativas da Pró-Rim ocorreu de forma concomitante a outras instituições na área da saúde como, por exemplo, o Hospital Israelita Albert Einstein, localizado em São Paulo, SP. ${ }^{3}$

Após a inserção na web 2.0, houve uma convergência de comunicação dessa prática de interação social entre usuários interessados em orientações de saúde e a equipe profissional res-

2 Com base na visão de Jenkins (2008) a convergência consiste em uma transformação cultural, à medida que consumidores são incentivados a procurar novas informações e fazer conexões em meio a conteúdos midiáticos dispersos. A convergência dos meios de comunicação, a inteligência coletiva e a cultura participativa compõem a cultura da convergência.

3 De acordo com a coordenadora de mídias digitais do Einstein, Elis Forgerini (2011), o hospital está há quase um ano neste ambiente de mídias digitais. Para estar inserido no atual ambiente digital, que inclui inúmeras outras iniciativas digitais, além da presença nas redes, o Hospital trabalhou sob um planejamento estratégico de um ano e meio, para mapear e avaliar todas as potenciais necessidades neste ambiente. 
ponsável pelo serviço “Dr. Online”, da instituição. Além do envio de e-mails por meio de formulários no site da instituição, as informações de saúde passaram a ser compartilhadas pelo Orkut, Facebook e Twitter.

Esses ambientes são espaços de interação e divulgação de informações sobre prevenção de doenças renais, casos de saúde e de qualidade de vida, envio de notícias e entrevistas, compartilhamento sobre relatos de histórias de pacientes renais, entre outros assuntos. Em aproximadamente três meses de presença nas redes sociais já possui 2.500 pessoas relacionadas, sendo 844 seguidores no Twitter, 803 amigos no Orkut e 626 amigos no Facebook. O gerenciamento das ações realizadas pela instituição nas redes sociais digitais é feito por uma jornalista analista de mídias digitais, chamada Lívia Vieira, que atua dentro do Departamento de Comunicação e Marketing da entidade.

Com o intuito de se identificar a visão da profissional sobre a interação dos pacientes nas redes, foi efetuada uma entrevista com a profissional no dia 8 de abril de 2011, por e-mail. De acordo com Vieira (2011), os temas de maior interesse no perfil da instituição nas redes digitais são as informações sobre os pacientes em vias de transplantes, informações institucionais e prevenção de doenças. Ao ser perguntada sobre como são as práticas sociais e de comunicação dos pacientes em cada ambiente e quais os pontos comuns e as particularidades, a profissional respondeu que os pontos comuns são a interatividade, o relacionamento e o grande potencial de divulgação das ações da Pró-Rim. Sobre o Facebook, enfatiza:

A possibilidade de "curtir" do Facebook é uma interação simples e ao mesmo tempo significativa para mensurar a receptividade dos conteúdos. Como esta rede propicia a conversa, temos muitos comentários. Apesar de não se conhecerem, as pessoas até ajudam umas às outras com dicas e palavras de apoio (VIEIRA, 2011).

Com o intuito de se aprofundar a análise nesta ferramenta, buscou-se realizar uma pesquisa quantitativa e qualitativa sobre o perfil da Fundação Pró-Rim e a participação de pacientes relacionada a esse perfil.

\section{Análise netnográfica: interação de pacientes no Facebook da Fundação Pró-Rim}

Com o objetivo de analisar as interações de pacientes renais pelas redes sociais da Fundação Pró-Rim, escolheu-se o Facebook ${ }^{4}$ por ser uma ferramenta em evolução e com poucas pesquisas realizadas nessa área. A metodologia de pesquisa aplicada foi a Netnografia. ${ }^{5}$ Conforme definições de Kozinets (2007), a netnografia é uma adaptação dos métodos qualitativos utilizados em pesquisa de consumo, antropologia cultural e estudos culturais, com o objetivo de proporcionar um estudo contextualizado do comportamento do consumidor dentro de comunidades virtuais e de produtos da cibercultura.

Nesse estudo, a aplicação da etnografia virtual teve início em dezembro de 2010. Desse período até o dia 10 de abril de 2011, realizou-se a entrée cultural no Facebook da Fundação Pró-Rim com o intuito de se conhecer os temas abordados e os tipos interação realizadas pelos pacientes renais

Para a coleta de dados, foi feito um recorte temporal dos primeiros 100 dias de presença da PróRim nas redes sociais, que ocorreu de 14 de dezembro de 2010 a 25 de março de 2011. As interações desse período foram catalogadas. Nessa classificação, observaram-se os seguintes dados (Tabela 1):

\footnotetext{
4 A rede social Facebook foi criada em 2004 por Mark Zuckerberg, Dustin Moskovitz e Chris Hughes, estudantes de Harvard, nos Estados Unidos. Inicialmente, consistia em uma rede social privada para os estudantes de Harvard, antes de se tornar acessível às outras universidades americanas. É o maior site de rede social do mundo.

5 A transposição da metodologia de etnografia para o estudo de práticas comunicacionais mediadas por computador recebe o nome de netnografia, ou etnografia virtual, e sua adoção é validada no campo da comunicação pelo fato de que "muitos objetos de estudo localizam-se no ciberespaço" (ROCHA; MONTARDO, 2005, p. 1).
} 
Tabela 1 - Número de interações no Facebook da PróRim

\begin{tabular}{lc}
\hline Posts & 134 \\
Comentários & 101 \\
Likes (Curtir) & 790 \\
Mensagens & 10 \\
\hline
\end{tabular}

Fonte: Dados da pesquisa.

Dos temas com maior interesseidentificou-se em primeiro lugar o transplante renal e também interações de pacientes sobre aspectos institucionais da entidade. Posts sobre serviços, equipe, eventos e entrevistas com profissionais apresentaram um nível alto de interesse e interações. Em interações mais clínicas, as interações dos pacientes ocorrem especialmente na busca de dicas e orientações sobre como tratar as doenças renais e sobre prevenção.

O post com maior interação e participação possuía o título "Macapaense fará transplante renal: Conheça a história de Laércio". A notícia indicava que o transplante ocorreria no dia posterior e relatava a história de um paciente do Macapá que foi à Santa Catarina em busca do transplante.

Essa postagem ocorreu no dia 17 de fevereiro de 2011; houve 24 interações, entre "likes" e comentários. Identificaram-se especialmente mensagens positivas de outros pacientes desejando sucesso no procedimento. Após esse post, houve várias manifestações espontâneas de outros pacientes buscando informações sobre o estado de saúde do transplantado. De acordo com a jornalista Lívia Vieira (2011), uma forma de responder a esses questionamentos dos pacientes no Facebook foi a elaboração de uma reportagem mostrando a condição de saúde do paciente após o procedimento, com um depoimento dele (Figura 1).

Outras interações ainda relacionadas ao transplante renal observadas foram as mensagens de pacientes com dúvidas sobre o procedimento, sobre como realizá-lo com a equipe da Fundação Pró-Rim e sobre tratamento posterior. Notou-se também a participação de pacientes buscando compartilhar as suas realidades sobre a doença. $\mathrm{Na}$ interação analisada na imagem, a seguir nota-se a mensagem de uma paciente de Portugal relatando a sua história (Figura 2).

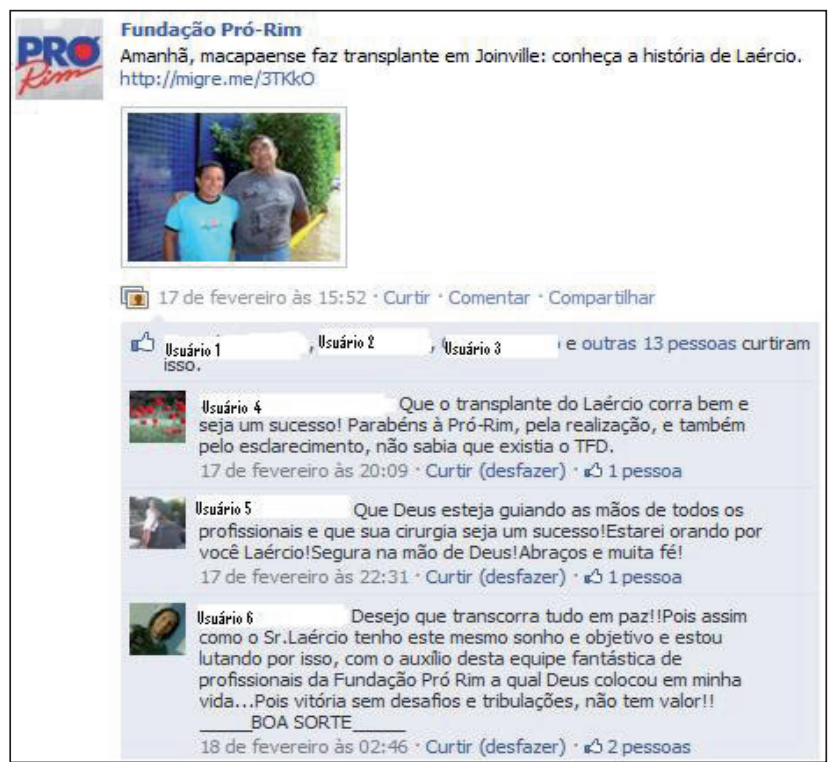

Figura 1 - Interação sobre transplante renal Fonte: Facebook, 2010.

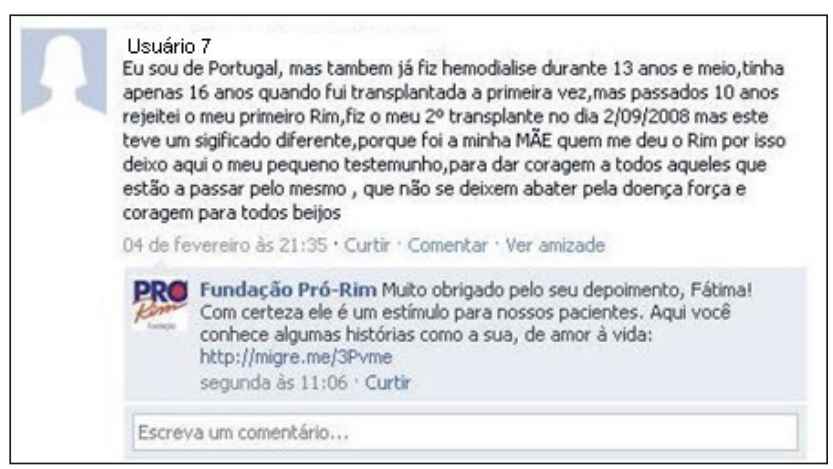

Figura 2 - Interação sobre transplante renal

Fonte: Facebook, 2010.

Com a coleta de dados e análise quantitativa foram identificados os 10 pacientes mais participativos. Desses, foi selecionado para entrevista um paciente que tivesse agendado consulta com a instituição para a realização do transplante após conhecê-la pelo Facebook. Essa informação foi identificada por meio de análise de conteúdo e foi confirmada por meio da observação participante e realização de entrevista com a analista de mídias sociais. Identificou-se que o usuário 6 foi um paciente participativo com essa característica. 
Para realização da entrevista, adicionou-se esse paciente como amigo e entrou-se em contato com ele pedindo autorização e convidando-o para a coleta de informações. A entrevista com ele aconteceu pela ferramenta de chat do Facebook no dia 6 de abril de 2011, das 19 h48 às 21h22. Após contato anterior pela rede, pediu-se a autorização do paciente para a realização da entrevista e explicou-se que a sua identidade seria preservada na pesquisa, conforme condições da netnografia, propostas por Kozinets (2007).

No roteiro da entrevista semiestruturada, foram preparados os seguintes itens, na ordem que segue:

1) hábitos de acesso às redes sociais;

2) práticas sociais e de comunicação com outros pacientes renais e profissionais de saúde atuantes nessa área;

3) temas de interesse nas interações e buscas de informações;

4) relacionamento com a Fundação PróRim pela rede social.

De acordo com o usuário entrevistado, a sua interação se dá mais no Facebook do que no Orkut. O entrevistado destacou que "o Facebook dá mais oportunidades de discussão em tempo real. Podemos interagir mais em determinados assuntos colocados" (USUÁRIO 6, 2011). Ao ser questionado sobre o seu uso do Orkut, ele enfatizou que ainda usa a rede social, pois possui amigos que não têm Facebook e que são pessoas com quem já tem contato há muito tempo: "Fico um pouco constrangido em simplesmente excluir" (USUÁRIO 6, 2011). Ao ser perguntado sobre o que mais procura nas redes sociais colaborativas, respondeu que são os seguintes itens: contato com pessoas do mesmo problema, busca de informações sobre tipos de tratamento e busca de informações e contato com hospitais onde são feitos transplante.

Segundo ele, a internet significa o seu maior meio de aprendizado e as informações que obtém nela lhe dão uma autonomia em relação ao seu tratamento e à busca dos seus direitos. "Os médicos tratam diferente quem entende do seu tratamento e buscam pelos seus direitos. Quando tenho que questionar ou não concordar com algo coloco minha posição” (USUÁRIO 6, 2011).
Sobre o diálogo virtual com outros pacientes e profissionais da saúde nas redes sociais online, o entrevistado destacou que encontra mais pacientes nas redes do que profissionais, mas que muitos pacientes não se expõem e não possuem informações sobre as suas realidades; não são tão esclarecidos. Enfatizou que uma prática de interação que busca no relacionamento com outros pacientes é o de promover ajuda.

Procuro saber se eles mantêm o controle hídrico, se conversam abertamente com seus familiares, se os mesmos são participativos [...] e sobre priorizarão do bem estar do paciente lhes falam das minhas experiências com medicamentos [...] mais é como the falei hoje em dia [...] espero sempre que alguém me solicite informação (USUÁRIO 6, 2011).

Quanto a sua relação com a Fundação Pró-Rim, ele contou que conheceu a instituição pelo Facebook por meio de uma interação pela ferramenta de chat:

Conheci a Fundação Pró rim no Facebook em uma das minhas buscas. Meu primeiro contato com um profissional de lá [...] foi no chat on line no Facebook...depois entrei no perfil [...] e vi que tinha um site [...] o qual entrei e fiquei maravilhadocom relatos depacientes devárias partes do Brasil[...] eresolvimandarume-mail, com solicitação de informações sobre transplante intervivos [...] já que tenho um possível doador. Tenho uma consulta pré transplante marcada para o dia 27/4 (USUÁRIO 6, 2011).

O paciente mora em Belém do Pará, região onde tratamento renal é muito precário e quase não se realiza o transplante. De acordo com entrevista de Darwich (2011), existem 800 pessoas em lista de espera por um rim e são realizados em média 34 transplantes renais por ano, no Estado. Em Santa Cantarina, somente a Pró-Rim faz por ano aproximadamente 90 transplantes. Em Santa Catarina, a média de espera para um paciente receber um rim de um doador cadáver é de três meses, tendo muitos já recebidos em até uma semana. Esse fato atrai muitos pacientes de outras regiões do Brasil, conforme exemplo do paciente entrevistado e as interações de outros pacientes. 
Por meio da análise netnográfica, observou-se que o perfil da Fundação Pró-Rim é um espaço de relacionamento social e de comunicação organizacional entre a entidade e os pacientes renais, mas se torna também um espaço de encontro e interação entre eles. Percebe-se esse caso como uma experiência interessante de relacionamento e de suporte aos pacientes crônicos em suas dúvidas e necessidades. Outras entidades e profissionais de saúde poderiam ampliar as suas ações de relacionamento nas redes sociais com pacientes, visando a aproveitar essa presença e apoiar as suas buscas de informações.

\section{Considerações finais}

As redes sociais têm-se tornado espaço propício para a chamada Health 2.0. Compartilhar informações e experiências sobre suas condições de saúde e buscar relacionamento com profissionais, estabelecimentos e outras pessoas em condições semelhantes são algumas das interações de pacientes nas redes sociais.

Esses espaços colaborativos contam com um número crescente de pacientes renais que se apropriam da rede para interação, engajamento, relacionamento com outros pacientes. Conversar, buscar e compartilhar informações sobre o transplante renal é uma das práticas sociais e de comunicação mais comuns por esse tipo de paciente.

Com as realidades diferentes nas regiões do Brasil, nota-se o comportamento de muitos pacientes renais identificando experiências relacionadas a esses procedimentos e apropriando-se das mídias sociais para conversar a respeito e até mesmo deslocar-se para regiões aonde ocorrem mais transplantes. Por meio das redes sociais, os pacientes têm promovido a ajuda mútua, buscado relacionamento com outros pacientes e compartilhado cada vez mais experiências. Todavia, é importante destacar que as participações desse público na rede bem como a obtenção de informações de saúde nas mídias sociais são complemento e ajuda aos pacientes que encontram no médico a orientação e o diagnóstico mais importante para os seus tratamentos.

Como busca de dados empíricos, analisou-se o caso da presença digital da Fundação PróRim e estudou-se como se dá a participação de pacientes renais dentro do seu perfil do Facebook.
Constatou-se que, assim pesquisas anteriores apontavam, a participação de pacientes nas redes sociais cresce e muitos se destacam por terem claras as suas intenções e interesses dentro da ferramenta.

Foi realizada uma entrevista em profundidade com um paciente renal do Belém do Pará que conheceu a Pró-Rim pelo Facebook e que marcou a sua consulta na Pró-Rim, em Santa Catarina, para inscrição na lista de transplante. Nessa conversa, identificou-se que o Facebook é uma ferramenta que tem crescido graças à disseminação de sua mensagem para todos os amigos. A conversa com o paciente destacou o conceito de "paciente expert" quando ele menciona que é mais respeitado em sua clínica por conhecer mais os seus direitos e por ser um paciente "antenado". Além disso, destaca a rede social digital como um espaço de ajuda mútua entre pacientes.

Com relação à interação dos pacientes com a Fundação Pró-Rim, enxerga-se a necessidade de se explorar ainda mais o seu perfil nas redes sociais, gerando um espaço maior de troca entre os pacientes, podendo a entidade agir como uma mediadora de discussões e troca de ideias. O relacionamento com os pacientes seria ainda mais explorado com a participação efetiva de profissionais de saúde da Fundação PróRim na web 2.0. Identificou-se também o potencial de explorar ainda mais o perfil colaborativo dos pacientes renais e a abertura para que o perfil da Pró-Rim seja um espaço propício para a criação de campanhas espontâneas e autoorganizadas e de uma participação em um nível mais avançado e maduro por parte dos pacientes, de acordo com as especificidades dos seus temas de interesse e envolvimento.

Um aspecto importante nessa análise trata do papel da rede social como um meio no qual os pacientes buscam não somente por informações e interações com pessoas semelhantes, mas também por esperança e qualidade de vida. Cabe às instituições de saúde enxergar esse contexto e identificar de que forma podem se posicionar, promover e oferecer suporte à colaboração dos seus públicos.

\section{Referências}

BELTRÁN, L. R. La importancia de la comunicación en la promoción de la salud. In: EPSTEIN, I. et al. (Org.). Mídia e saúde. Adamantina: UNESCO/UMESP/FAI, 2001. p. 355-368. 
DARWICH, C. DOL Entrevista: à espera de um transplante. 15 mar. 2011. Disponível em: <http://www. diarioonline.com.br/noticia-139452-dol-entrevista-a-espera-de-um-transplante.html>. Acesso em: 8 abr. 2011.

FACEBOOK. Fundação Pró-Rim. Disponível em: $<$ http://pt-br.facebook.com/prorim>. Acesso em: 28 set. 2010.

FORGERINI, E. Entrevista concedida a Andréia Jacopetti, Joinville, SC, pelo e-mail andreiajacopetti@ hotmail.com, no dia 14 de abril de 2011.

FOX, S.; JONES, S. The social life of health information. Pew Internet \& American Life Project, Washington, 2009. Disponível em: <http://www. pewinternet.org/Reports/2009/8-The-Social-Life-ofHealth-Information.aspx>. Acesso em: 10 set. 2010.

GARBIN, H. B. da R.; PEREIRA NETO, A. de F.; GUILAM, M. C. R. A internet, o paciente expert e a prática médica: uma análise bibliográfica. Interface Comunicação, Saúde e Educação, v. 12, n. 26, p. 579-588, 2008.

JENKINS, H. Cultura da convergência. São Paulo: Aleph, 2008.

KOTLER, P.; SHALOWITZ, J.; STEVENS, R. J. Marketing estratégico para a área da saúde: a construção de um sistema de saúde voltado ao cliente. Porto Alegre: Artmed, 2010.

KOZINETS, R. V. Netnography 2.0. In: BELK, R. W. (Ed.). Handbook of qualitative research methods in marketing. Cheltenham, UK: Edward Elgar Publishing, 2007. p. 129-142.

PESSONI, A. A comunicação para a saúde como campo de estudos e pesquisas. Comunicação \& Saúde, v. 2, n. 3, 2005. Disponível em: <http://www.comunicasaude.com.br/revista/03/entrevista.asp > . Acesso em: 15 ago. 2010.

RICE, R. E. The Internet and health communication - a framework of experiences. In: RICE, R. E.; KATZ, J. E. (Ed.). The Internet and health communication: experience and expectations. Thousand Oaks, CA: Sage, 2001. p. 5-46.

ROCHA, P. J.; MONTARDO, S. P. Netnografia: incursões metodológicas na cibercultura. e-compós, Brasília, v. 4, p. 2-22, 2005. Disponível em: <http:// http://www.compos.org.br/seer/index.php/e-compos/article/viewFile/55/55>. Acesso em: 2 abr. 2010.
USUÁRIO 6. Entrevista concedida a Andréia Jacopetti, Joinville, SC, pelo e-mail andreiajacopetti@hotmail.com, no dia 6 de abril de 2011.

VIEIRA, L. Entrevista concedida a Andréia Jacopetti, Joinville, SC, pelo e-mail andreiajacopetti@hotmail.com, no dia 8 de abril de 2011.

Recebido: 20/02/2011

Received: 02/20/2011

Aprovado: 25/04/2011

Approved: 04/25/2011 